\title{
MOMA: the challenge to search for organics and biosignatures on Mars
}

\author{
W. Goetz', W. B. Brinckerhoff ${ }^{2}$, R. Arevalo Jr. ${ }^{2}$, C. Freissinet ${ }^{2}$, S. Getty ${ }^{2}$, \\ D. P. Glavin ${ }^{2}$, S. Siljeström ${ }^{3}$, A. Buch ${ }^{4}$, F. Stalport ${ }^{5}$, A. Grubisic ${ }^{2}$, X. Li ${ }^{2}$, V. Pinnick ${ }^{2}$, \\ R. Danell 6 , F. H.W. van Amerom ${ }^{7}$, F. Goesmann', H. Steininger', N. Grand ${ }^{5}$, \\ F. Raulin ${ }^{5}$, C. Szopa ${ }^{8}$, U. Meierhenrich 9 , J. R. Brucato ${ }^{10}$ and the MOMA Science \\ Team ${ }^{1,2,3,4,5,6,7,8,9,10, i ~}$ \\ ${ }^{1}$ MPS, Göttingen, Germany e-mail: goetz@mps.mpg.de \\ ${ }^{2}$ NASA GSFC, Greenbelt, MD, USA \\ ${ }^{3} S P$ Technical Research Institute of Sweden, Borås, Sweden \\ ${ }^{4}$ LPGM, Ecole Centrale Paris, Chatenay-Malabry, France \\ ${ }_{5}^{5}$ LISA, U. Paris-Est, Créteil, U. Paris Diderot, Paris, CNRS, France \\ ${ }^{6}$ Danell Consulting, Winterville, NC, USA \\ ${ }^{7}$ Mini-Mass Consulting, Hyattsville, MD, USA \\ ${ }^{8}$ LATMOS, Guyancourt, France \\ ${ }^{9}$ U. Nice, France \\ ${ }^{10}$ INAF - Astrophysical Observatory of Arcetri, Firenze, Italy \\ ${ }^{11}$ U. Bremen, Germany
}

\begin{abstract}
This paper describes strategies to search for, detect, and identify organic material on the surface and subsurface of Mars. The strategies described include those applied by landed missions in the past and those that will be applied in the future. The value and role of ESA's ExoMars rover and of her key science instrument Mars Organic Molecule Analyzer (MOMA) are critically assessed.
\end{abstract}

Received 22 January 2016, accepted 10 May 2016

Key words: MOMA, Mars, ExoMars rover, organic, biosignature, life, perchlorate.

\section{Introduction}

Questions on Mars' habitability (ancient or modern) are essentially tied to the history of liquid water on Mars. Surface features related to or caused by liquid water exist over a wide range of length scales (Fig. 1) and were formed at different times: liquid water is believed to have formed ancient valley networks and outflow channels in the Martian highlands (Fig. 1(a) and (b)) (Carr 2012) as well as recent gullies (Fig. 1 (c)) and current seasonal flows on warm slopes (Fig. 1(d)) (McEwen et al. 2014). Based on VIS/NIR reflectance spectra (acquired from orbit) these seasonal flows likely consist of aqueous solutions of perchlorate salts (Ojha et al. 2015). In contrast to these faint signs of episodic surface liquid water on modern Mars (Fig. 1(c) and (d)), sedimentary deposits, encountered at great variety in Gale crater, the landing site of the Curiosity rover (Fig. 1(e) and (f)), indicate sustained overland flow of liquid water early in the planet's history (Williams et al. 2013; Grotzinger et al. 2015). While modern Mars is an aeolian planet marked by long-standing volcanic activity and with only sporadic liquid water (likely in the form of brines) at its surface, ancient Mars appears to have had localized environments that would have been compatible with the requirements of primitive terrestrial life (Grotzinger et al. 2014). The question if life ever evolved on or near the surface of Mars is of great importance and must be addressed by ever-evolving experimental techniques. While past and present landed missions to Mars
(Fig. 2) have been designed to inform our understanding of contextual surface geochemistry and mineralogy (i.e. Mars Pathfinder, the Mars Exploration Rovers and the Curiosity Rover, which included goals of studying the organic geochemistry of Mars), three of these landed missions were designed and carried out as biology missions: the Viking Landers (VL-1 and VL-2) and the Phoenix Mars Lander. The label 'biology' does not so much refer to 'biology experiments' per $s e$, but emphasizes the enhanced requirements for cleanliness of flight hardware, which is required for any spacecraft that is designed to search for and characterize organic compounds as evidence for a potential (ancient or modern) microbial habitat. The Viking Landers and the Phoenix mission are particularly important to understand the prevailing landscape in which the next mission is under development that will search for past and present biology on Mars: the ExoMars rover.

The Viking Landers carried instrumentation (Soffen \& Snyder 1976) to conduct the following, highly ambitious experiments: (1) thermal volatilization-gas chromatographymass spectrometry (TV-GC-MS) and (2) three biology experiments: (2a) Gas Exchange (GEx), (2b) labelled release (LR) and $(2 \mathrm{c})$ pyrolytic release (PR). The goal of these experiments was to search for organic compounds in the Martian soil (TVGC-MS) and to search for signs of metabolism (GEx, LR, PR). The details of these experiments are given in Table 1. Briefly, it was investigated if 'soil' would react with nutrients 

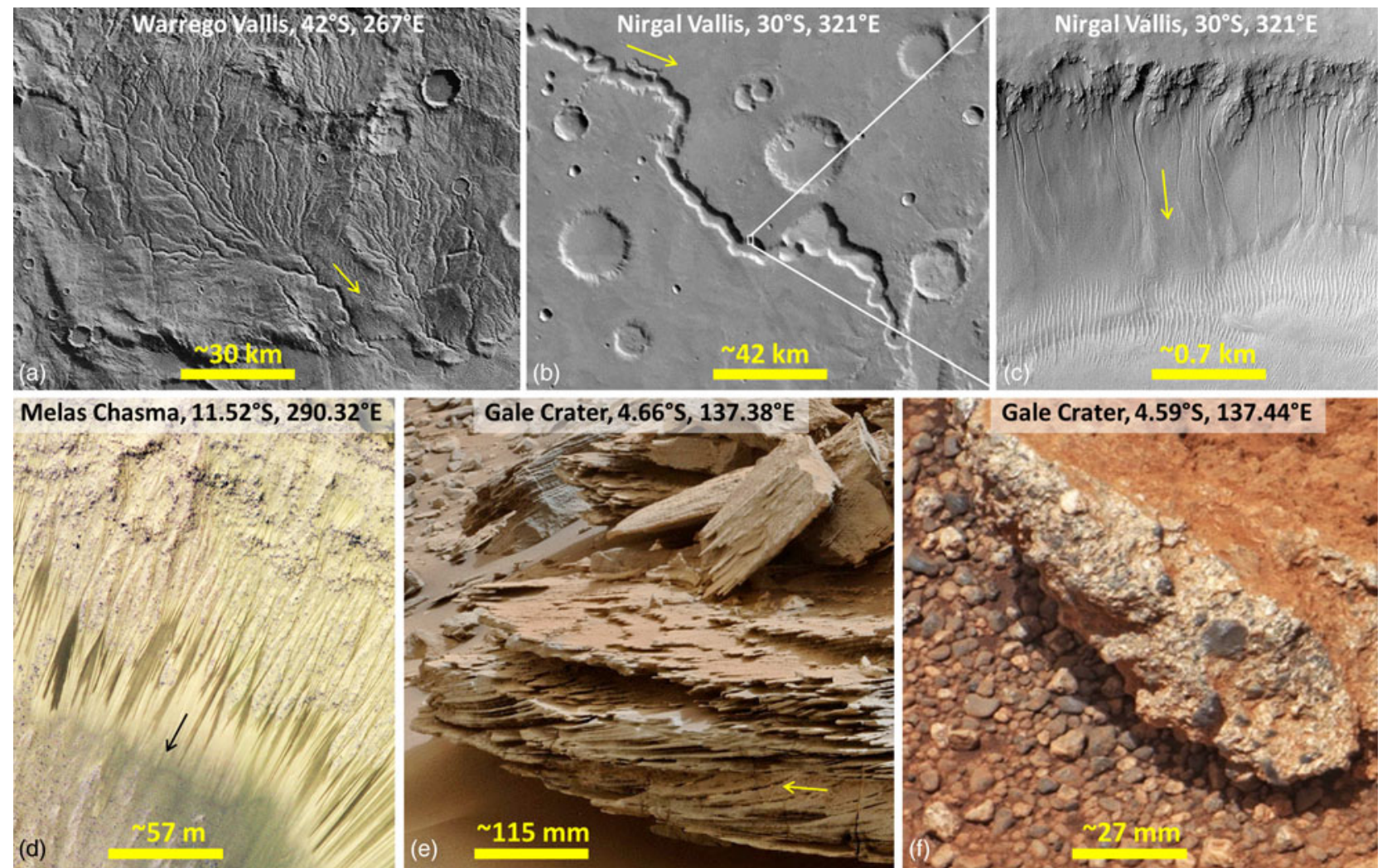

Fig. 1. Signs of liquid water on (ancient and modern) Mars, (roughly) sorted according to increasing magnification: (a) Example of ancient (noachian) dissected valley networks on Mars' southern hemisphere. Warrego Vallis may be among the most dissected ones (Ansan \& Mangold 2006; Carr 2012). (b) Example of (mostly hesperian) outflow channels with young gullies (c) on the channel wall. (d) Recurring Slope Lineae (RSL) on the wall of a crater in Melas Chasma (part of Valles Marineris) (McEwen et al., 2014). (e) Cross-laminated sandstone (Whale rock, sol 796) in the Pahrump area, Gale crater. (f) Conglomerate Link (sol 27) near the Bradbury landing site of the Curiosity rover, Gale crater. Supplemental Online Material (SOM) Figures 1 and 2 provide context images (with wider field of view) for Figures 1e and 1f, respectively. Flow directions indicated by arrow in $(\mathrm{a}-\mathrm{d})$. North is up in images (a-d). Credit: NASA/JPL/MSSS. Image (e) presents a view towards SSE $\left(\sim 160^{\circ}\right)$. However, there is uncertainty if the imaged sediment block is still in place, or has been rotated since deposition. Hence flow direction cannot be inferred from that image in an absolute sense.

under release of gases, e.g. $\mathrm{CO}_{2}(\mathrm{GEx})$, and if soil would release ${ }^{14} \mathrm{CO}_{2}$ if reacting with ${ }^{14} \mathrm{C}$ labelled nutrients (LR). Finally, it was also investigated, if 'soil' would be able to build up a more complex molecule (such as carbohydrates) in presence of UV radiation (intense on the surface of Mars) and/or water vapour (PR). It was hypothesized that the positive detection of any of these by-products would be suggestive of an active metabolism on the surface of Mars, pointing to extant life. In fact, the results of these experiments were complex and could not be interpreted as being 'clearly positive' or 'clearly negative' (ten Kate 2010 and references therein).

A particular result of the TV-GC-MS experiment onboard VL-1 was the detection of $\sim 15 \mathrm{ppm}$ chloromethane that had not been detected by the blank experiment during cruise, and detection of dichloromethane (VL-2) at a higher level than during cruise (Biemann et al. 1977). These results suggest that TV-GC-MS experiments at the VL-1 and VL-2 landing sites generated chlorinated methanes, originating from Mars surface chemistry in the upper $10 \mathrm{~cm}$. As the measured isotope ratios of these compounds ${ }^{35} \mathrm{Cl} /{ }^{37} \mathrm{Cl}(\sim 3: 1)$ were found to be very close to the terrestrial value, the results were interpreted to be caused by terrestrial contamination from chlorinated laboratory solvents used during hardware development or by the reaction of adsorbed traces of methanol and $\mathrm{HCl}$ in the Viking GC-MS instruments (Biemann et al. 1977). Still, Biemann et al. (1977) could not rule out the possibility that some of the chloromethane was indigenous to the sample.

The Viking biology experiments also returned some unexpected results: The results returned by LR were particularly puzzling (simultaneously producing both 'positive' and 'negative' indicators) and still today cannot be explained in a satisfactory way (ten Kate 2010). During the GEx experiment, the addition of nutrients led immediately to the release of molecular oxygen $\left(\mathrm{O}_{2}\right)$. Upon addition of more nutrients, the amount of generated oxygen decreased steadily. This observation is incompatible with a biogenic interpretation as the nutrients should not have any sterilizing effect on potential microbes in the sample. Later on, inorganic pathways (invoking peroxides) were found that could largely explain these observations (Quinn \& Zent 1999; ten Kate 2010). In retrospect, the apparent absence of organic material in the soil (as based on TV-GC-MS) seems to rule out microbial life in the soil. Arguably a clear, positive finding of extant life on 


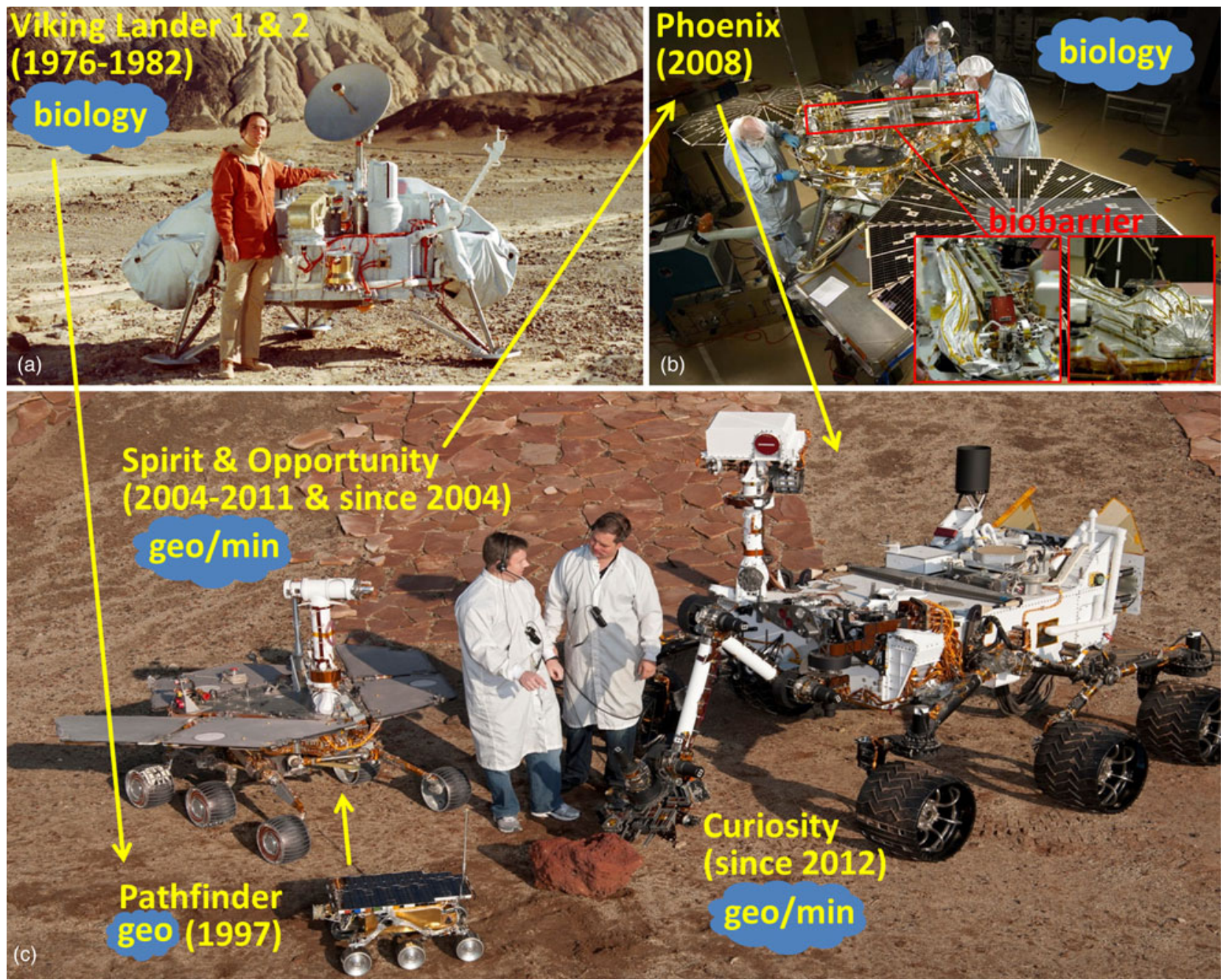

Fig. 2. NASA's landed missions with timeframes of operations on the surface of Mars. These missions served primarily geology/geochemistry, mineralogy or biology (labeled, respectively, by "geo", "min" and "biology"). (a) Model of the Viking landers in Death Valley, California, USA (Carl Sagan, 1934-1996). SOM-Figure 3 shows a view of the Martian landscape acquired by Viking Lander 2 including its aluminum biobarrier. (b) Phoenix Mars Lander during assembly. Also shown the Phoenix biobarrier in open and closed state (made of tedlar or $\left[\mathrm{CH}_{2}-\mathrm{CHF}_{\mathrm{n}}\right.$, gas-tight cover of the critical robotic arm). (c) The family of Mars rovers in JPL's Mars Yard. Credit: NASA/JPL.

Mars would have at least required a clear positive and repeatable response from all four experiments (TV-GC-MS and biology experiments).

The scientific community has largely held this consensus interpretation of Viking Lander results since the 1970s. However, results of the Phoenix mission (PHX, May-October 2008) raised new questions. Data from the Wet Chemistry Laboratory (WCL) onboard Phoenix provided unambiguous proof of $\sim 0.5 \mathrm{wt} \%$ perchlorate in the soil (Hecht et al. 2009). That abundance is similar to (or higher than) the highest abundances of perchlorate in terrestrial arid regions, such as the Atacama Desert, Chile (Fig. 1 in Catling et al. 2010). Indeed, certain terrestrial microbes are known to make use of perchlorate in anaerobic conditions as a source of energy (Catling et al. 2010 and references therein). Neither organic carbon nor perchlorate was directly detected by the TV-MS instrument (TEGA, Thermal and Evolved Gas Analyser, also onboard Phoenix). Whereas thermal decomposition of perchlorate would be expected to evolve chlorine, in fact, chlorine gas would have corroded the nickel ovens (by formation of nickel chloride, Lauer et al. 2009) or reacted with the water present in the sample and in the instrument to form $\mathrm{HCl}$, and was therefore undetectable. TEGA instead detected $\mathrm{O}_{2}$ in a single experiment (presumably from thermal decomposition of perchlorate, sol 24, Lauer et al. 2009), little water vapour and significant amounts of $\mathrm{CO}_{2}$, attributable in part to thermal decomposition of $\mathrm{CaCO}_{3}$ (Boynton et al. 2009). The presence of chlorine in ordinary Martian soil has long been known from X-ray fluorescence experiments onboard the Viking Landers, the Sojourner rover (Mars Pathfinder, July-October 1997) and the Mars Exploration Rovers (Fig. 2). So far, it had been common thinking that all chlorine existed as chloride anion, but WCL data showed that more than $90 \%$ of all chlorine in Martian (arctic) soil was present as $\mathrm{ClO}_{4}$ anion. Still, some uncertainty remained on the identity of the cation in the perchlorate compound (candidates were $\mathrm{Mg}^{2+}, \mathrm{K}^{+}, \mathrm{Na}^{+}$and $\mathrm{Ca}^{2+}$. 
Table 1. Pyrolysis and biology experiments onboard the Viking Landers

\begin{tabular}{|c|c|c|}
\hline Name & Science question & Experimental procedure \\
\hline $\begin{array}{l}\text { Thermal volatilization } \\
\text { (TV-GC-MS) }\end{array}$ & $\begin{array}{l}\text { Soil }+ \text { heat } \rightarrow \text { organic volatiles? } \\
\text { Does 'Martian soil' contain organic compounds that } \\
\text { would release characteristic volatiles during pyrolysis? }\end{array}$ & $\begin{array}{l}\text { An oven charge of Martian soil }\left(\sim 60 \mathrm{~mm}^{3}\right) \text { heated (within }<8 \mathrm{~s} \text { ) } \\
\text { to } 200,350 \text { and } 500^{\circ} \mathrm{C} \text {, then detect and identify volatiles by GC- } \\
\text { MS }\end{array}$ \\
\hline Gas exchange (GEx) & $\begin{array}{l}\text { Soil }+ \text { nutrients } \rightarrow \text { gases released? } \\
\text { Are nutrients decomposed by 'Martian soil'? }\end{array}$ & $\begin{array}{l}\text { Up to } 1000 \mathrm{~mm}^{3} \text { soil mixed with aqueous solution of nutrients } \\
\text { (mainly amino acids, (in)organic salts), then monitor compos- } \\
\text { ition of gas phase [initially } \mathrm{CO}_{2}, \mathrm{Kr}, \mathrm{He}, 200 \text { mbar (total pres- } \\
\text { sure)] above that mixture over the course of } 106 \text { days }\end{array}$ \\
\hline Labelled release (LR) & $\begin{array}{l}\text { Soil }+{ }^{14} \mathrm{C} \text { nutrients } \rightarrow{ }^{14} \mathrm{CO}_{2} \text { released? } \\
\text { [same question as for } \mathrm{GEx}]\end{array}$ & $\begin{array}{l}\text { Same as for GEx, but using }{ }^{14} \mathrm{C} \text { labelled nutrients, then (after } 2 \\
\text { days of incubation time) monitor release of }{ }^{14} \mathrm{CO}_{2} \text { by a Geiger } \\
\text { counter }\end{array}$ \\
\hline Pyrolytic release (PR) & $\begin{array}{l}\mathrm{Soil}+{ }^{14} \mathrm{CO}_{2}\left(+\mathrm{UV}, \mathrm{H}_{2} \mathrm{O}\right) \rightarrow{ }^{14} \mathrm{C} \text { sugars? } \\
\text { Are nutrients built up by 'Martian soil' under con- } \\
\text { sumption of energy? }\end{array}$ & $\begin{array}{l}\text { Up to } 1000 \mathrm{~mm}^{3} \text { soil mixed with }{ }^{14} \mathrm{CO}_{2} \text {, some of these samples } \\
\text { were additionally mixed with water vapour and/or irradiated by } \\
\text { UVA/VIS (Xe lamp, } \lambda>320 \mathrm{~nm} \text { ), after incubation time ( } ~ 5 \\
\text { days) the gas was carefully removed and the sample was 'com- } \\
\text { busted' with oxidants }\left(\mathrm{CuO}, 640^{\circ} \mathrm{C} \text { ), finally monitor release of }\right. \\
{ }^{14} \mathrm{CO}_{2} \text { by Geiger counter (as for LR) }\end{array}$ \\
\hline
\end{tabular}

It became a fast general thought that perchlorate is a globally occurring compound, especially if it is formed by chemical processes in the atmosphere (Catling et al. 2010, although questioned and refined by Smith et al. 2014). The perchlorate finding opened up a new view of Martian soil in general, and suggested reinterpretation of some of the Viking results: (1) VL-1 found exclusively chloromethane, whereas VL-2 found dichloromethane only. (2) VL-1 found $\sim 8$ times less chlorine than VL-2 (Navarro-Gonzalez et al. 2010). Currently it is unclear how and if these two observations are related to each other. Navarro-Gonzalez et al. (2010) performed laboratory experiments on Mars analogue samples (soil from Atacama, Chile, containing $\sim 32 \mathrm{ppm}$ of organic carbon), but this time with and without magnesium perchlorate. In the presence of $1 \mathrm{wt} \%$ magnesium perchlorate, they were able to produce mono- and dichloromethane, both by experiment and by theoretical modelling. Surprisingly, only these two molecules were detected. Although Viking did not have the capability to identify perchlorates at the landing sites, based on these experiments and kinetic models, Navarro-Gonzalez et al. (2010, 2011a) suggested that there could have been ppm levels of Martian organic carbon at both Viking landing sites. This organic material could be biogenic or, more likely, a result of the continuous organic-rich micrometeoritic influx $\left(0.2 \times 10^{6} \mathrm{~kg}\right.$ $\mathrm{C} \mathrm{yr}^{-1}$; Flynn 1996). However, this conclusion did not remain uncontested: Biemann \& Bada (2011) questioned the validity of Navarro-Gonzalez et al.'s analogue experiments that used a commercial GC-MS instrument rather than a setup similar to the Viking instrument. This challenge has then been debated again (Navarro Gonzalez et al. 2011b).

The expectation that perchlorate should be a global soil component was further substantiated by the SAM instrument (Sample Analysis at Mars, Mahaffy et al. 2012) onboard the Curiosity rover. To date (mid-January 2016) SAM has received one scooped sample (Rocknest sand deposit, Glavin et al. 2013) and nine drilled rock samples for pyrolysis experiments. All these samples released $\mathrm{O}_{2}$ and $\mathrm{HCl}$, generally accompanied by chlorinated hydrocarbons (e.g. chloromethane and dichloromethane) (Archer et al. 2013, 2016; Glavin et al. 2013). These observations are consistent with the presence of oxychlorine species (i.e. perchlorates and/or chlorates) in all samples. Interestingly, the $\mathrm{O}_{2}$ peak that is used as a proxy for such oxychlorine species evolves over a wide temperature range $\left(100-600^{\circ} \mathrm{C}\right)$ indicating that the term 'oxychlorine species' likely captures a variety of salts, including perchlorates and chlorates (with $\mathrm{Ca}^{2+}, \mathrm{Mg}^{2+}, \mathrm{Fe}^{2+}$ and $\mathrm{Na}^{+}$being the most likely cations). Moreover, the occurrence of oxychlorine species in all samples (Rocknest soil as well as sedimentary rocks) suggests that oxychlorine has been formed over most of Mars's history (Archer et al. 2016). More recently, these species have also been found in Martian meteorite EETA79001 (Kounaves et al. 2014). In the following, we use the term 'perchlorates' for simplicity, keeping in mind that other oxychlorine species are likely involved.

Arvidson et al. (2010) demonstrated that the concentration of mineral(oid)s that can be dissolved in water under certain conditions varies strongly within the work area of a Mars rover (Spirit). Similarly, the concentration of (water-soluble) perchlorates can also vary strongly over small spatial scales. In fact, SAM found very little perchlorate at the drill site John Klein (drilling performed on sols 180 \& 182) and a very high abundance of perchlorate at Cumberland (drilling on sol 279), although both drill sites were only a few metres from each other (Archer et al. 2016). Chemical and mineralogical composition are broadly similar at both sites, except that John Klein contains 2-3 times less chlorine and 2-3 times more sulphur (present as anhydrite \& bassanite) than Cumberland (McLennan et al. 2014; Vaniman et al. 2014). John Klein (contrary to Cumberland) has numerous subsurface fractures/veins (Supplemental Online Material (SOM), Figs. 4 and 5), hence John Klein may have been depleted in chlorine (perchlorate) by fluid circulation through these fractures that were later filled by a $\mathrm{CaSO}_{4}$ phase (as part of a late diagenetic event). Organic molecules (chlorobenzene and dichloroalkanes) were found mainly at Cumberland, not at John Klein (SOM-Fig. 4), but it was later shown that this effect was caused by a different 
experimental protocol applied at both sites (the one applied to John Klein led to an inadvertent loss of released organic compounds to the Martian atmosphere), not by a true chemical difference between both sites (Freissinet et al. 2015). A lot of efforts have been made to correct the acquired raw data for the SAM background that is known to be elevated. Eventually, Freissinet et al. (2015) reported an equivalent abundance of $\sim 200 \mathrm{ppbw}$ chlorobenzene and up to 70 ppbw $\mathrm{C}_{2}-\mathrm{C}_{4}$ dichloroalkanes in the Cumberland outcrop. This result is the first in situ detection and quantification of Martian indigenous organic material. Unfortunately, the effect of perchlorate on pyrolysis data cannot be assessed from these two data sets as we are missing adequate and comparable pyrolysis data for John Klein.

In summary, perchlorates are ubiquitous in Martian soils and rocks, although at varying abundances. Their chemical reactivity is highest at their temperatures of thermal decomposition due to release of reactive gases such as oxygen and chlorine. All pyrolysis experiments performed so far (Viking Landers, Phoenix, Curiosity) were strongly affected by perchlorates that react with indigenous Martian organics and potential terrestrial organic contaminants in a mineral/rock matrix. The minerals can act as catalysts for certain chemical reactions. A lot of analogue laboratory experiments have been performed in order to better understand Martian pyrolysis experiments and to obtain clues on the parent organic material that resides in Martian soils/rocks. Steininger et al. (2012) contributed a case study on the influence of perchlorate on the pyrolysis of benzoic acid and mellitic acid on a basaltic substrate. Similarly, Miller et al. (2013, 2015) investigated the chlorination of aromatic compounds, functionalized or not, while pyrolysed in the presence of perchlorates. Clearly, pyrolysis of organics in the presence of perchlorate leads to chlorination and/or combustion of organic molecules, and a competition occurs between those two reactions. The end products depend on the type of products to be pyrolysed and on the temperature. Steininger et al. (2012) chose mellitic acid for their case study, because that acid might be a metastable intermediate product of an oxidative degradation of meteoritic organic material and thus a representative molecule for the current organic inventory on Mars (Benner et al. 2000; Archer et al. 2009). Steininger et al. (2012) found a very different behaviour of benzoic and mellitic acid during pyrolysis and concluded that the following types of molecules have the best chance to 'survive' this type of aggressive pyrolysis (i.e. to be chlorinated rather than combusted): (i) organic molecules containing the least relative number of oxygen atoms (ideally no oxygen at all), and (ii) organic molecules containing the highest relative number of $\mathrm{C}-\mathrm{H}$ groups, with $\mathrm{C}$ participating in an aromatic functional group. In contrast to these results, Miller et al. (2013, 2015) found that, while functionalized aromatics (benzoic acid and phthalic acid) will readily chlorinate during pyrolysis in the presence of Ca-perchlorate, non-functionalized aromatics (benzene and toluene) will not. Both works together suggest that functionalized and fairly reduced aromatics may be representative of indigenous Martian organic material from which the volatile compounds (as detected during pyrolysis) were derived.

\section{The astrobiological concept of the ExoMars rover}

The current status of the in situ search for organic compounds in the Martian near-surface material (soils and rocks) was described in the previous section. A brief overview of organic material in Martian meteorites can be found in Steininger et al. (2012). Which requirements must be imposed on a future Mars rover mission that shall search for organic compounds on the Martian surface and address their biogenic or abiotic origin? So far, the search for Martian organics was moderately successful: Simple (chlorinated) organic molecules evolved during pyrolysis of drill fines of sedimentary outcrop (Yellowknife Bay, Gale Crater; Freissinet et al. 2015) and were clearly identified as part of the indigenous inventory of Martian organic material. Their parent molecules that reside in the sedimentary rock are poorly constrained or unknown. Also we do not know if that organic material is associated with a specific mineral phase. Given these unknowns, the most meaningful approach to continue the in situ exploration of 'organic Mars' is the combination of previously applied experimental techniques with new ones such that given samples acquired at a future landing site will be analysed by both 'old' and 'new' techniques. In that way, new data can be compared with those from previous missions and continuity along all landed Mars missions is ensured, until samples are brought back from Mars.

The ExoMars rover (to be launched in 2020, Fig. 3) is part of the (bigger) ESA-Roscosmos ExoMars project that includes its precursor, the ExoMars orbiter mission (Trace Gas Orbiter (TGO) that was launched on March 14, 2016). In addition to its important science goals (e.g. characterize the variable methane concentration in the Martian atmosphere), TGO shall serve as the prime communication link for the ExoMars rover. The high-level science goals of the ExoMars rover, in order of priority, are: (i) to search for signs of past and present life on Mars, and (ii) to characterize the water/geochemical environment as a function of depth in the shallow subsurface (quoted in full, credit: ESA 2014). The instrument payload, by which the ExoMars rover shall achieve these science goals, falls into two groups: (1) a set of macroscopic colour cameras needed for (autonomous and manual) rover navigation and for reconnaissance and spectral characterization of remote targets, and (2) a set of analytical instruments that are designed to analyse samples from the rock drill and crusher. The latter analytical instruments include: (2a) VIS/NIR hyperspectral imager (MicrOmega) to characterize the mineralogy of all grains within its field of view $\left(\mathrm{FOV}, 5 \times 5 \mathrm{~mm}^{2}\right)$ at a spatial resolution of $\sim 20 \mu \mathrm{m}$, (2b) the Raman Laser Spectrometer (RLS) to explore the mineralogy and chemistry within its FOV $(\sim 50 \mu \mathrm{m})$, and (2c) MOMA, the Mars Organic Molecule Analyser, a versatile mass-spectrometer-based instrument to explore the chemistry (especially organic chemistry) of the samples. More details on the science payload are given in Table 2.

Notably absent from the ExoMars science payload is instrumentation to determine the bulk chemical composition of a sample (e.g. by X-ray fluorescence). Hence, there is no direct means 


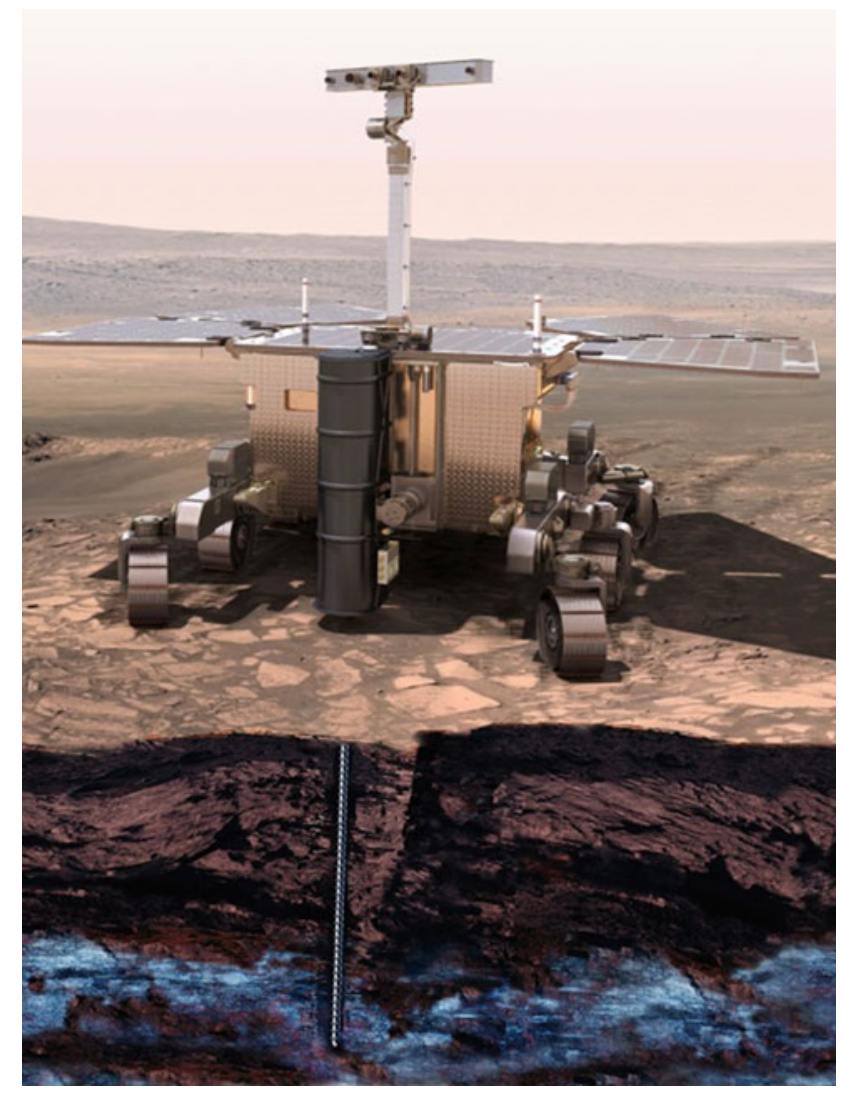

Fig. 3. Current design of the ExoMars rover (as of January 2016). Credit: ESA. http://exploration.esa.int/mars/51499-exomars-rover/ (accessed January 19, 2016).

on the rover to determine the total amount of major elements such as $\mathrm{Si}, \mathrm{Fe}$ or $\mathrm{S}$ in the sample. However, the high-level science focus of the rover mission is to characterize the organic compounds in Martian sedimentary rocks, and to characterize the context of these organic compounds, i.e. to establish their associations with minerals and with rock type. In fact, the rover will be capable to identify in reconnaissance mode (Pancam, ISEM, see Table 2) unusual targets of potential astrobiological significance, such as opaline silica outcrops (Ruff \& Farmer 2015, 2016) or rocks rich in carbonates (Morris et al. 2010). Despite the severe constraints on mass and electrical power (unlike the Curiosity rover, the ExoMars rover is solar-powered), the rover nevertheless manages to support significant novel analytical-laboratory payload elements (MicrOmega, Raman, MOMA) that serve that science focus very well.

The most important capability of the ExoMars rover (Fig. 3) is, after mobility, its capability to drill down to $2 \mathrm{~m}$ into the Martian subsurface, retrieve a drill core from that depth, and crush it for analysis by the analytical laboratory. The main focus of the mission will be sedimentary outcrops that have been minimally perturbed or disturbed since their initial deposition. Experimental and modelling work has shown that Martian rocks (including organic inventory) at a depth of $2 \mathrm{~m}$ are well protected against particle radiation from the sun (solar cosmic rays, SCR) or from space (galactic cosmic rays, GCR) (Kminek \& Bada 2006; Pavlov et al. 2012) and thus also against oxidants formed by this radiation. Energetic particles (mostly protons and alpha particles) interact with organic compounds in Martian rocks in the following ways (Pavlov et al. 2012): (a) Fragmentation: Organic molecules are fragmented by the impact of an incident particle. The probability for such a process increases with increasing molecular weight. (b) Secondary oxidation: Organic molecules are oxidized by radical molecules that are generated by the impact of an incident particle on the silicate or oxide lattice of rock-forming minerals. Both types of processes cause a modification ('processing') of the organic part of Martian sediments. In principle, the generated organic molecules can react with neighbour molecules (repolymerization and/or crosslinking), if the latter are available. However, at low abundance in organic material (as typical for Mars) the generated products may be lost as volatiles implying a steady depletion of (near-)surface sediments in total organic carbon.

Recent experiments (Pavlov et al. 2016) showed that the destruction rate of pure (and dry) amino acids is exacerbated if the latter are captured by dry silica powder, and that the destruction rate is greatly enhanced if water is present in the amino acid/silica mixture, probably because water molecules are a good source of radical molecules in the radiative environment (see process (b) above). Additionally, the presence of liquid water (that may be in the form of nanometre-thick layers on mineral grains) accelerates dramatically the racemization of amino acids, should they have been produced with enantiomeric excess by a putative (extinct) Martian biota (Bada \& McDonald 1995). Although (ancient) liquid water is a strong tracer for (ancient) habitability on the surface of Mars (see Introduction section), hydrated minerals (at the surface or near-subsurface) appear to be 'the worst place to look for intact ancient organic molecules on Mars' (Pavlov et al. 2016). In summary, the topmost metre of Martian sediments is significantly affected by particle radiation over a timescale of much less than a billion years (mostly due to GCRs, as SCRs only reach the topmost few centimetres of surface rocks) implying the necessity to acquire samples below that radiative zone (deeper than $\sim 1 \mathrm{~m}$ ) for organic analysis.

Obviously, in the case of a complex depositional scenario (e. g. with distinct depositional and erosional eras) we cannot know if a modern subsurface sample (acquired e.g. at a depth of $1 \mathrm{~m}$ ) has indeed been protected against particle radiation over the entire time since deposition. However, the simpler scenario with (say) deposition of a particular sediment that was (rapidly) buried under later sediments and then re-exposed by continuous long-term denudation (such as proposed for Curiosity's work area in northwestern Gale crater, Grotzinger et al. 2015) should also be a frequent case on the surface of Mars considering the overall low tectonic activity of Mars over the past two billion years (Amazonian era). In particular, SAM noble gas analysis of the Cumberland mudstone showed that the cosmic ray exposure age of $\sim 80 \mathrm{Ma}$ was much younger than the $\sim 4 \mathrm{Ga}$ rocks that made up the mudstone itself (Farley et al. 2014). Thus, it is plausible that the rover could uncover organic-bearing sediments that experienced mainly ordinary diagenesis (such as sediment burial and circulating aqueous fluids), rather than strong radiation levels 
Table 2. Science Payload for the ExoMars rover mission, consisting of the solar-powered rover (ESA) and lander platform (Roscosmos). Most instruments listed are mounted to the body, mast or drill of the rover; the lowermost row provides an abbreviated list of instruments onboard the lander platform. The goal of this table is to illustrate the synergy of different payload elements. The instruments within the Analytical Laboratory Drawer ( ALD) of the rover body (MicrOmega, RLS, MOMA) can only analyze powdered samples derived from the drill and delivered by the rover's Sample Processing and Distribution System (SPDS). MicrOmega can characterize the mineralogy of the sample as well as detect some organic compounds (provided the latter are exposed on grain surfaces and have absorption bands in the NIR region, i.e. at $\lambda \leq 3.7 \mu \mathrm{m})$. MicrOmega's large field of view $(F O V)\left(5 \times 5 \mathrm{~mm}^{2}\right)$ provides the context for 'point' measurements by RLS $(\sim 0.05 \mathrm{~mm})$ and MOMA $(\sim 0.3 \mathrm{~mm})$. MOMA's operational modes are listed (further details in Table 3)

\begin{tabular}{|c|c|c|c|}
\hline Science addressed & Instrument description or experimental technique & $\begin{array}{l}\text { Instrument } \\
\text { name }\end{array}$ & Where? \\
\hline Morphology, mineralogy & Multispectral panoramic camera & Pancam & Rover mast \\
\hline Mineralogy & Point/line reflectance spectrometer (VIS/NIR) & ISEM & \\
\hline Morphology & Close-Up Imager, colour CCD & CLUPI & $\begin{array}{l}\text { Rover drill chassis } \\
\quad \text { (outside) }\end{array}$ \\
\hline Mineralogy, chemistry & $\begin{array}{l}\text { Hyperspectral imager (VIS/NIR reflectance), FOV: } 5 \times \\
5 \mathrm{~mm}^{2} \text {, spatial res. } \sim 20 \mu \mathrm{m}\end{array}$ & MicrOmega & Rover body (inside) \\
\hline Mineralogy, chemistry & Point/line Raman spectrometer (RLS) & RLS & \\
\hline Chemistry, focus on organic compounds & $\begin{array}{l}\text { (1) Pyrolysis-GC-MS } \\
\text { (2) Derivatization-GC-MS and thermochemolysis- } \\
\text { GC-MS } \\
\text { (3) LDI-MS }\end{array}$ & MOMA & \\
\hline Structure of subsurface (few metres) & Emission and detection of reflected RADAR waves & WISDOM & Rover body (out- \\
\hline Subsurface water $(\sim 1 \mathrm{~m})$ & Passive neutron detector & ADRON & side, rear) \\
\hline Mineralogy & Point/line reflectance spectrometer (VIS/NIR) & MaMISS & Rover drill (inside) \\
\hline $\begin{array}{l}\text { Atmosphere \& dust, subsurface } \mathrm{T}(\sim 1 \mathrm{~m}) \text {, sub- } \\
\text { surface water }(\sim 1 \mathrm{~m}) \text {, seismic }\end{array}$ & \multicolumn{2}{|c|}{$\begin{array}{l}\text { Cameras, meteo-package ( } \mathrm{p}, \mathrm{T} \text {, wind), LIDAR, GC-MS (atmospheric } \\
\text { composition), Fourier spectrometer (atmospheric trace gases), active } \\
\text { neutron detector, seismometer }\end{array}$} & Lander platform \\
\hline
\end{tabular}

over geologic timescales. In summary drilling into a depth of $2 \mathrm{~m}$ is a very significant step forward to access 'pristine sediments' that have preserved a significant part of their original organic inventory in terms of structure, cross-linking, molecular mass and perhaps also functional groups. This is the window back in time that the ExoMars rover needs in order to address the biological potential of Martian rocks.

\section{The MOMA approach}

Among all science payload elements (Table 2), MOMA is most directly focused on the high-level science goals of the ExoMars rover mission. MOMA is an international effort (see institutes affiliated to the MOMA Science Team) with flight hardware to be provided by MPS \& LZH (Germany), LISA \& LATMOS (France) and NASA GSFC (USA).

MOMA has three operational modes (Table 3): (i) pyrolysis-GC-MS, (ii) derivatization/thermochemolysis-GC-MS and (iii) Laser Desorption and Ionization (LDI)-MS.

First of all, it can be seen that the 'heart' of the MOMA instrument, common to all three operational modes, is the MS (provided by NASA GSFC, for detailed description see Arevalo et al. 2015). The MS will be operated in the range from some 'threshold mass' ( $50 \mathrm{Da}$ ) and up to $1000 \mathrm{Da}$ (depending on the operational mode, Table 3). Although that mass threshold can be changed during operations, MOMAMS is not designed to detect light molecules that are either part of the Martian atmosphere or that evolve during pyrolysis (e.g. $\mathrm{CO}_{2}, \mathrm{~N}_{2}, \mathrm{O}_{2}, \mathrm{CH}_{4}, \mathrm{HCl}$ ). More importantly, due to strict weight limitations, the MS is designed to detect only cations, not anions. That is a somewhat unfortunate restriction that precludes direct detection of chlorates and perchlorates (see Introduction section).

Here is a brief description of MOMA's operational modes as listed above. The first two operational modes are currently applied by SAM onboard the Curiosity rover (see Introduction section) and are also commonly applied in Earth-based analytical laboratories in order to enable GC-MS analysis of fairly volatile and less volatile organic compounds. These compounds are either converted to lower-mass fragments ('pyrolysis') or their polarity is reduced by chemical reaction with a derivatization agent (DA) ('derivatization') or both processes are applied at the same time ('thermochemolysis'). In the following, 'thermochemolysis' will be dealt with as part of 'derivatization' (in a broad sense). According to MOMA's first operational mode, a crushed sample from the drill is transferred to any one of $\sim 20$ pyrolysis ovens (out of a total of $\sim 32$ MOMA ovens) of the carousel (Fig. 4), then pyrolysed at any desired temperature $\left(<900^{\circ} \mathrm{C}\right)$. Released volatile molecules are entrained by a continuous He flow and accumulated in a hydrocarbon trap. After pyrolysis the trap is emptied by flash-heating in backflush mode at $300^{\circ} \mathrm{C}$ and released volatiles are separated and detected by GC-MS. A MOMA pyrolysis experiment, performed in the field (Svalbard, Norway) with flight-like submodules of the MOMA instrument, has been described by Siljeström et al. (2014).

Alternatively, according to MOMA's second operational mode, the sample is only heated to some (moderately high) 


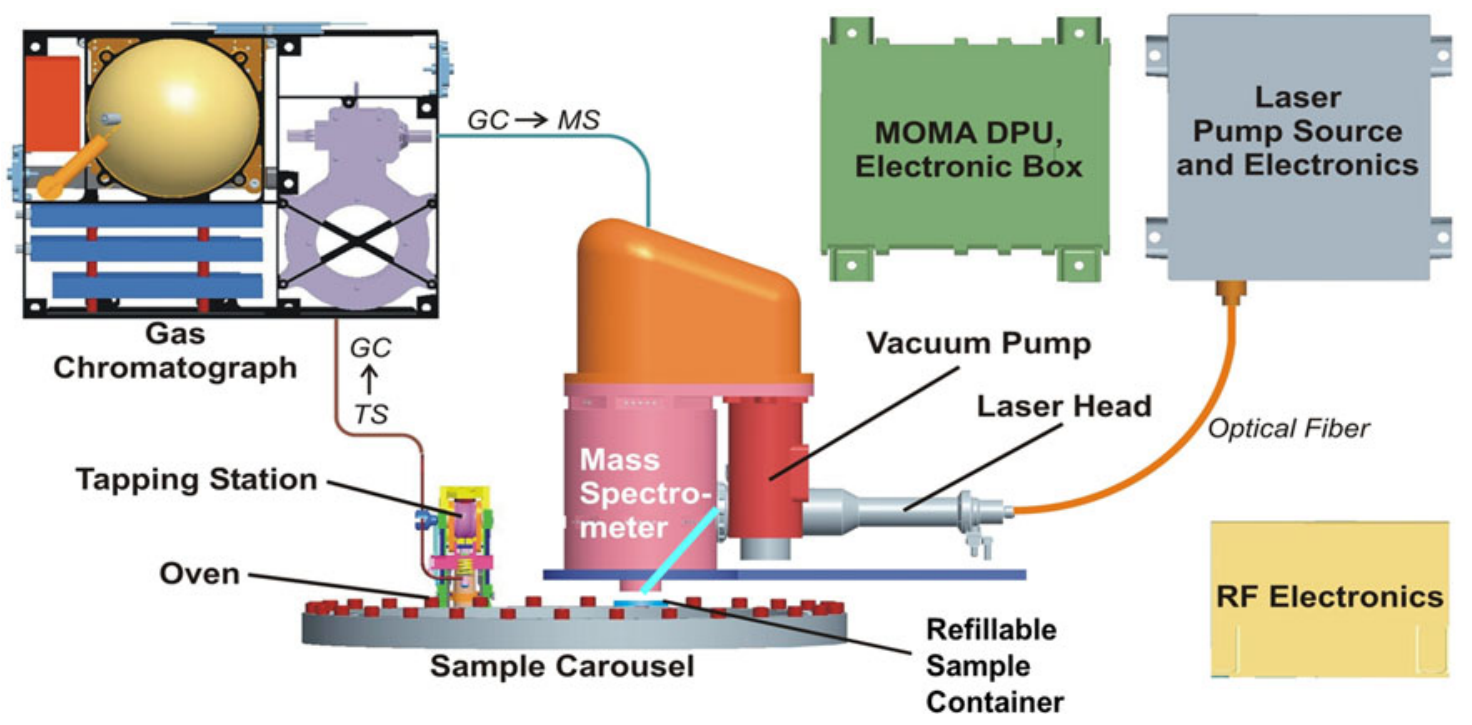

Fig. 4. Overview of the MOMA instrument (Goetz et al. 2011). The inclined thick solid line (drawn in blue-green color) represents the laser beam that hits the sample in the refillable sample container at $45^{\circ}$.

Table 3. MOMA operational modes: pyrolysis, derivatization/thermochemolysis and LDI. The derivatization agents (DAs) are: MTBSTFA/DMF (N-tert-butyldimethylsilyl-N-methyltrifluoroacetamideldimethylformamide as a 3:1 mixture), DMF-DMA (N,N-dimethylformamide-dimethylacetal) or TMAH (25 wt\% tetramethylammonium hydroxide in methanol). The compounds given in square brackets behind the $D A$ are the targeted classes of organic compounds in the sample that will be volatilized by chemical reaction with that specific DA in order to be analysed by the GC-MS part of MOMA. The UV laser needed for LDImode has a power density of (up to) $5 \times 10^{11} \mathrm{~W} \mathrm{~m}^{-2}$ per pulse. This power density is at least 20 times smaller than the one used for Laser Induced Breakdown Spectroscopy applied by the ChemCam instrument onboard the Curiosity rover (Maurice et al. 2012)

\begin{tabular}{|c|c|}
\hline Principles & Hardware \& technique \\
\hline PYROLYSIS-GC-MS & $\begin{array}{l}\text { - } \sim 150 \mathrm{~mm}^{3} \text { sample } \rightarrow \sim 800^{\circ} \mathrm{C} \\
\text { - Four different } \mathrm{GC} \text { columns (including enantioselective) } \\
\text { - Detect mass range } 50-500 \mathrm{Da}\end{array}$ \\
\hline DERIVATIZATION-GC-MS \& & - $\sim 150 \mathrm{~mm}^{3}$ sample $\rightarrow 100-300^{\circ} \mathrm{C}$ \\
\hline THERMOCHEMOLYSIS-GC-MS & $\begin{array}{l}\text { - Add one of the following DAs: } M T B S T F A / D M F \text { (carboxylic \& amino acids, nucleobases, } \\
\text { amines, alcohols) DMF-DMA (amino acids, fatty acids, primary amines, transformed with } \\
\text { preservation of } \mathrm{C}^{*} \text { ) } \\
\text { TMAH (lipids, fatty acids) } \\
\text { - Detect mass range } 50-500 \mathrm{Da}\end{array}$ \\
\hline LDI-MS & $\begin{array}{l}\text { - UV laser: } \lambda=266 \mathrm{~nm}, \leq 135 \mu \mathrm{J} \text { pulse }{ }^{-1} \text {, pulse duration } \sim 1.3 \mathrm{~ns} \text {, bursts } \leq 100 \mathrm{~Hz} \text { (average } 2 \mathrm{~Hz} \text { ) } \\
\text { - Probed sample: } \sim 400 \mu \mathrm{m} \times 600 \mu \mathrm{m} \text {, depth approximately a few and up to } 10 \mathrm{~nm}^{-1} \operatorname{shot}^{-1} \\
\text { - Detect mass range } 100-1000 \mathrm{Da}\end{array}$ \\
\hline
\end{tabular}


of homochirality or enantiomeric excess of potential Martian amino acids will be the highest science goal of the ExoMars rover mission. A derivatization experiment involving DMFDMA would have been performed by the COSAC instrument onboard Philae, Rosetta's landing spacecraft for comet 67P/ Churyumov-Gerasimenko, if landing on that comet had occurred nominally (Meierhenrich et al. 2001; Goesmann et al. 2007, 2015). Tetramethylammonium hydroxide (TMAH) is more aggressive (and can be used up to higher temperatures, e.g. between 600 and $700^{\circ} \mathrm{C}$ ), but can volatilize lipids and fatty acids, and even more refractory compounds such as polyaromatic hydrocarbons or kerogen.

Finally, MOMA's third operational mode, LDI-MS, is a totally different analytical technique and involves a different sample path: this time, crushed sample from the drill is transferred to the refillable sample container (Fig. 4). The surface of the powderized sample is flattened by a scraper and can then be examined by MicrOmega, RLS or MOMA-LDI. In the latter case, bursts of UV pulses ablate $\sim 10 \mathrm{~nm}$ of material per shot (depending on the mineral or rock type, Goetz et al. 2016) that is guided through an ion inlet, a fast aperture valve, and differential pressure gates to the MS. The fast aperture valve is required because the sample in the refillable sample container is at Martian atmospheric pressure $(\sim 8$ mbar or $\sim 6$ Torr $\mathrm{CO}_{2}$ ), whereas the linear ion trap (LIT) of the MS must be operated at a pressure $<10^{-3}$ Torr (Pinnick et al. 2016).

The material ablated by the laser pulses includes larger intact molecular (inorganic or organic) ions and fragments, thus MOMA-LDI (as opposed to pyrolysis or derivatization) is a fairly non-destructive method. In that sense, MOMA-LDI is highly complementary to MOMA-pyrolysis and MOMAderivatization and also to other non-destructive analysis methods onboard (MicrOmega, RLS). A significant part of the previous section was devoted to the complex interplay between organic compounds and perchlorates during pyrolysis. Li et al. (2015) have shown that MOMA-LDI data are relatively insensitive to the presence of perchlorates in the sample.

\section{Discussion and outlook}

So far, the present paper was devoted to the following questions: What do we currently know about organics on Mars? What are the current plans for future exploration? It is clear that the in situ search for and detection of Martian organics is difficult, leading to a 'Martian dilemma': It has been shown by many authors (Steininger et al. 2012 and references therein) that a significant amount of organic material should have been brought to Mars over its entire history. According to a simple calculation (Steininger et al. 2012) 60 ppm organic $\mathrm{C}$ would be expected in a global, $100 \mathrm{~m}$ thick regolith layer, assuming constant micrometeoritic influx (equal to the modern one) over $4.6 \mathrm{Ga}$ and assuming no degradation over time. Despite these assumptions, a value of $60 \mathrm{ppm} \mathrm{C}$ is also consistent with the abundance of organic carbon (the fraction believed to be indigenous of Mars) in SNC meteorites (see Table 1 in Steininger et al. 2012 and references therein). So why has in situ detection of organic material been so sparse up to now? Are natural processes on Mars working against these experiments? Are the in situ applied analytical methods inappropriate?

There are several possibilities:

(1) Radiation problem:

The degradation of organic compounds on the surface of Mars is faster than the supply of organic material by meteoritic influx. That would imply a very low abundance (or absence) of organic material at or near the surface of Mars, except in (e.g. recently exposed) outlier areas. The degradation of organic material might be driven either directly by UV (Poch et al. 2014, 2015) or particle radiation (GCRs, SCRs; Pavlov et al. 2012), or by oxidized reactive species, such as superoxide radicals (Yen et al. 2000; Georgiou et al. 2007) that again are generated by radiation. Perchlorate salts are fairly inert in the laboratory at low temperatures (like those on the Martian surface). However, in the Martian radiative environment these perchlorates may be slowly converted into reactive fragments (perhaps over a geologic timescale) that in turn react with organic compounds. Hence, the chemical reactivity of Martian soils (and also rocks) is critically linked to ionizing radiation.

(2) Combustion problem:

A significant inventory of organic material on today's Martian surface may not have been detected by pyrolysis (the principal method so far applied to search for Martian organic material) due to presence of perchlorates that are inert at low ambient temperatures (at least on a short (not geologic) timescale), but have a strong oxidizing potential at high temperatures.

(3) Extraction problem:

A significant inventory of organic material on today's Martian surface may not have been detected due to intrinsic inefficiency of methods used to date (e.g. pyrolysis) in extraction of that material from the sedimentary rock or from the mineral phase to which it is associated. This is the case for highly refractory carbonaceous magmatic phases (abiotic macromolecular carbon) such as found in ten Martian basaltic meteorites (Steele et al. 2012). On Earth, clay minerals are known to host a large amount of strongly bound (not easily extractable) organic material due to their high specific surface (Hedges \& Keil 1995) and their preservation in the interlayers (Ehrenfreund et al. 2011). Accordingly, mudstones have a high biopreservation potential. But, what about Mars? Is Martian organic material necessarily associated with clay minerals?

The difficulty to detect Martian organic material may be caused by one or several among the above listed problems.

If the radiation problem is dominant, then the ExoMars rover strategy will benefit from the rover's capability to retrieve drill samples from a depth of $\sim 2 \mathrm{~m}$ (Kminek \& Bada 2006; Pavlov et al. 2012).

If combustion and/or extraction are the dominant problem, then laser-based techniques, i.e. MOMA-LDI (Li et al. 2015) 
and Raman spectroscopy, may be the analytical methods of choice provided that the laser powers are low enough in order to prevent thermal decomposition of organic material.

If combustion is the dominant problem, then MOMA derivatization-GC-MS may also be a viable strategy provided that the experiment is performed below the temperature of thermal decomposition of 'perchlorates'. The latter condition is hard to specify precisely as a wide range of (per)chlorates seem to be present on the surface of Mars (see Introduction section). SAM has already been performing successful 'opportunistic derivatization' experiments utilizing a background level of MTBSTFA that escaped from one of its capsules (Glavin et al. 2013; Freissinet et al. 2015), but a full derivatization experiment where a sample is dropped into and allowed to react directly with MTBSTFA fluid in a filled capsule is currently being planned for operation on Mars.

Whatever the challenge, the ExoMars rover concept should be a robust strategy to search for and characterize Martian organic material. However, even with this approach, the ExoMars rover mission is not guaranteed to answer unambiguously the most fundamental questions, i.e. the question of biogenic or abiogenic origin of any indigenous organic material on the surface of Mars, and a specific correlation of that material to the occurrence of life on Mars, past or present. The potential conclusion 'Life on Mars' would be promptly challenged by the planetary science community and it would fail, if just one single argument (among the many arguments required) was not solid, e.g. due to instrument artefacts, contamination issues, possible inorganic pathways, conflicting datasets, lack of reproducibility of a given experiment etc. The question 'Life on Mars?' cannot be separated from the question on the origin of 'Life on Earth'. Hence, answering the question 'Life on Mars?' may well become a long scientific process of defining appropriate experimental techniques and protocols and developing plausible and safely applicable life criteria for ancient (terrestrial or Martian) sediments. However, by virtue of its science payload and its drill capability, the ExoMars rover mission will provide new types of data that will promote this process.

In this respect, NASA's Mars 2020 rover should be mentioned because: (1) its science payload includes two Raman spectrometers ('SuperCam', a mast-mounted instrument for fast reconnaissance as well as 'SHERLOC', a robotic-arm mounted for contact science and high spatial resolution), and, more importantly, (2) this rover may take the first step towards Mars Sample Return by obtaining returnable solid samples. Unfortunately, the rover's science payload does not include an analytical chemistry instrument like MOMA. Hence, there is no way to assess the biopotential of surface samples and use this information in order to preselect such samples for later return to Earth. If MOMA succeeds in detecting organic signatures suggestive of a possible biological origin in 'deep' samples, the surface samples preselected by the Mars 2020 rover may not be prioritized for return to Earth. Rather, MOMA will have led the way to which samples will have to be returned, those sheltered from degrading radiation and/or oxidation. In the long run, however, in situ analytical instruments, regardless of their capacity to characterize organic compounds in rocks, will not suffice to determine uniquely the origin of these compounds. The question of 'life on Mars' will be finally answered in full by repeated, cross-correlated investigations of the 'nano-structure' of Martian surface materials, i.e. by the systematic study of the spatial distribution of minerals, organics, and redox potentials in Martian samples on a nano-scale, and by extensive comparison to the oldest terrestrial sediments. Such studies will require Mars Sample Return.

\section{Supplementary material}

The supplementary material for this article can be found at http://dx.doi.org/10.1017/S1473550416000227.

\section{Acknowledgements}

This work was supported by DLR grant No. 50QX1401. Support for the mass spectrometer subsystem of MOMA under development at Goddard is provided by NASA's Mars Exploration Program (David Lavery, Program Executive). J. R. Brucato acknowledges ASI/INAF Agreement n. 20015-002-R.0. S. Siljeström acknowledges support from the Swedish National Space Board (Contract No. 121/11 and 198/15) and the Swedish Research Council (Contract No. 2015-04129). Discussions on the MOMA project at Göttingen Academy of Sciences and Humanities provided useful input to the manuscript. A. A. Pavlov, GSFC, Greenbelt, provided advice on degradation of organic compounds on the surface of Mars. N. Mangold, Univ. of Nantes, contributed to Fig. 1. Some excellent comments by two anonymous reviewers are gratefully acknowledged.

\section{References}

Ansan, V. \& Mangold, N. (2006). New observations of Warrego Valles, Mars: evidence for precipitation and surface runoff. Planet. Space Sci. 54, 219-242.

Archer, P.D., Jr. et al. (2009). UV photolysis of Mellitic acid - a possible organic at the Mars Phoenix Landing Site, LPSC, 2077.

Archer, P.D., Jr. et al. (2013). Possible detection of perchlorates by Evolved Gas Analysis of Rocknest soils: Global implications, LPSC, 2168.

Archer, P.D., Jr. et al. (2016). Oxychlorine species on Mars: implications from Gale crater samples, LPSC, 2947.

Arevalo, R., Jr. et al. (2015). Design and demonstration of the mars organic molecule analyzer (MOMA) on the ExoMars 2018 Rover. IEEE Aerospace Conference (March 2015), 1-11. doi: 10.1109/AERO.2015.7119073.

Arvidson, R.E. et al. (2010). Spirit Mars Rover Mission: overview and selected results from the northern Home Plate Winter Haven to the side of Scamander crater. J. Geophys. Res. Planets 115, E00F03. doi: 10.1029/2010JE003633.

Bada, J.L. \& McDonald, G.D. (1995). Amino acid racemization on mars: implications for the preservation of biomolecules from an extinct Martian biota. Icarus 114, 139-143.

Benner, S.A., Devine, K.G., Matveeva, L.N. \& Powell, D.H. (2000). The missing organic molecules on mars. Proc. Natl. Acad. Sci. USA 97(6), 2425-2430.

Biemann, K. \& Bada, J.L. (2011). Comment on "Reanalysis of the Viking results suggests perchlorate and organics at midlatitudes on Mars" by 
Rafael Navarro-Gonzalez et al. J. Geophys. Res. 116, E12001. http://dx. doi.org/10.1029/2011JE003869.

Biemann, K. et al. (1977). The search for organic substances and inorganic volatile compounds in the surface of mars. J. Geophys. Res. 82(28), 4641-4658.

Boynton, W.V. et al. (2009). Evidence for calcium carbonate at the mars phoenix landing site. Science 325, 61-64.

Carr, M. (2012). The fluvial history of Mars. Phil. Trans. R. Soc. A 370, 2193 2215. doi: 10.1098/rsta.2011.0500.

Catling, D.C. et al. (2010). Atmospheric origins of perchlorate on mars and in the atacama. J. Geophys. Res. 115, E00E11. doi: 10.1029/2009JE003425.

Ehrenfreund, P. et al. (2011). Astrobiology and habitability studies in preparation for future Mars missions: trends from investigating minerals, organics and biota. Int. J. Astrobiol. 10(3), 239-253. doi: 10.1017/ S1473550411000140.

ESA (2014). http://exploration.esa.int/mars/45082-rover-scientific-objectives/ (last update: 14 March 2014; accessed 19 January 2016).

Farley, K.A. et al. (2014). In situ radiometric and exposure age dating of the Martian surface. Science 343, 1247166-1. doi: 10.1126/science.1247166.

Flynn, G.J. (1996). The delivery of organic matter from asteroids and comets to the early surface of mars. Earth Moon Planets 72, 469-474.

Freissinet, C. et al. (2015). Organic molecules in the sheepbed mudstone, gale crater, mars. J. Geophys. Res. Planets. 120, 1-20, doi: 10.1002/2014JE004737.

Georgiou, C.D., Papapostolou, I., Sun, H. \& McKay, C.P. (2007). Superoxide radical assays and applications in Mars-like Atacama soils. J. Geophys. Res. Biogeosci. 112, G04S13. doi: 10.1029/2006JG000390.

Glavin, D.P. et al. (2013). Evidence for perchlorates and the origin of chlorinated hydrocarbons detected by SAM at the Rocknest aeolian deposit in Gale Crater. J. Geophys. Res. Planets 118, 1955-1973. doi: 10.1002/jgre.20144.

Goetz, W., Steininger, H., Goesmann, F. \& The entire MOMA Team (2011). Searching for Martian Organics with the Mars Organic Molecule Analyzer (MOMA) aboard ExoMars-2018, EPSC-DPS Joint Meeting, Nantes, France (Oct. 2011), EPSC-DPS2011 6, Abstr. \#1281. http:// meetingorganizer.copernicus.org/EPSC-DPS2011/oral_program/8824.

Goetz, W. et al. (2016). Characterization of mineral targets by Laser Desorption and Ionization in preparation of the MOMA investigation onboard the ExoMars rover, LPSC, Abstr. \#2614.

Grotzinger, J.P. et al. (2014). A habitable fluvio-lacustrine environment at Yellowknife Bay, Gale Crater, Mars. Science 343, 1242777-1. doi: 10.1126/science. 1242777 .

Grotzinger, J.P. et al. (2015). Deposition, exhumation, and paleoclimate of an ancient lake deposit, Gale crater, Mars. Science 350, aac7575. doi: $10.1126 /$ science.aac7575.

Goesmann, F. et al. (2007). COSAC, the commentary sampling and composition experiment on philae. Space Sci. Rev. 128, 257-280. doi: 10.1007/s11214-006-9000-6.

Goesmann, F. et al. (2015). Organic compounds on comet 67P/ChuryumovGerasimenko revealed by COSAC mass spectrometry. Science 349, aab0689-1. doi: 10.1126/science.aab0689.

Hecht, M.H. et al. (2009). Detection of perchlorate and the soluble chemistry of Martian soil at the phoenix lander site. Science 325, 64-67.

Hedges, J.I. \& Keil, R.G. (1995). Sedimentary organic matter preservation: an assessment and speculative synthesis. Mar. Chem. 49, 81-115.

Kminek, G. \& Bada, J.L. (2006). The effect of ionizing radiation on the preservation of amino acids on Mars. Earth Planet. Sci. Lett. 245, 1-5.

Kounaves, S.P., Carrier, B.L., O’Neil, G.D., Stroble, S.T. \& Claire, M.W. (2014). Evidence of Martian perchlorate, chlorate, and nitrate in Mars meteorite EETA79001: implications for oxidants and organics. Icarus 229, 206-213. doi: 10.1016/j.icarus.2013.11.012.

Lauer, H.V. Jr. et al. (2009). Thermal and evolved gas analysis of magnesium perchlorate: implications for perchlorates in soils at the mars phoenix landing site, LPSC, \#2196.

Li, X. et al. (2015). Detection of trace organics in mars analog samples containing perchlorate by laser desorption/ionization mass spectrometry. Astrobiology 15(2), 104-110. doi: 10.1089/ast.2014.1203.

Mahaffy, P.R. et al. (2012). The sample analysis at Mars investigation and instrument suite. Space Sci. Rev, 170, 401-478. doi: 10.1007/ s11214-012-9879-z.
Maurice, S. et al. (2012). The chemcam instrument suite on the mars science laboratory (msl) rover: science objectives and mast unit description. Space Sci. Rev. 170, 95-166. doi: 10.1007/s11214-012-9912-2.

McEwen, A. et al. (2014). Recurring slope lineae in equatorial regions of Mars. Nat. Geosci. 7, 53-58. doi: 10.1038/NGEO2014.

McLennan, S.M. et al. (2014). Elemental geochemistry of sedimentary rocks at Yellowknife Bay, Gale Crater, Mars. Science 343, 1244734-1. doi: 10.1126/science. 1244734 .

Meierhenrich, U., Thiemann, W.H.-P. \& Rosenbauer, H. (2001). Pyrolytic methylation assisted enantioseparation of chiral hydroxycarboxylic acids. J. Anal. Appl. Pyrolysis 60, 13-26.

Miller, K.E. et al. (2013). Analogue experiments identify possible precursor compounds for chlorohydrocarbons detected in SAM, abstract P23B-1785, Fall Meeting AGU, San Francisco, Calif. http://adsabs. harvard.edu/abs/2013AGUFM.P23B1785M.

Miller, K.E. et al. (2015). Evaluation of the Tenax trap in the Sample Analysis at Mars instrument suite on the Curiosity rover as a potential hydrocarbon source for chlorinated organics detected in Gale Crater. $J$. Geophys. Res. Planets 120, 1446-1459. doi: 10.1002/2015JE004825.

Morris, R.V. et al. (2010). Identification of carbonate-rich outcrops on mars by the spirit rover. Science 329, 421-424. doi: 10.1126/science. 1189667.

Navarro-González, R., Vargas, E., de la Rosa, J., Raga, A.C. \& McKay, C.P. (2010). Reanalysis of the viking results suggests perchlorate and organics at mid-latitudes on mars. J. Geophys. Res.- Planets 115(E12), E12010. doi: 10.1029/2010JE003599.

Navarro-Gonzalez, R., Vargas, E., de la Rosa, J., Raga, A.C. \& McKay, C.P. (2011a). Correction to "Reanalysis of the Viking results suggests perchlorate and organics at mid-latitudes on Mars". J. Geophys. Res. 116, E08011. doi: 10.1029/2011JE003854.

Navarro-Gonzalez, R. \& McKay, C.P. (2011b). Reply to comment by Biemann and Bada on "Reanalysis of the Viking results suggests perchlorate and organics at midlatitudes on Mars". J. Geophys. Res. 116, E12002. doi: 10.1029/2011JE003880.

Ojha, L. et al. (2015). Spectral evidence for hydrated salts in recurring slope lineae on Mars. Nat. Geosci. 8, 829-832. doi: 10.1038/NGEO2546.

Pavlov, A.A., Vasilyev, G., Ostryakov, V.M., Pavlov, A.K. \& Mahaffy, P. (2012). Degradation of the organic molecules in the shallow subsurface of Mars due to irradiation by cosmic rays. Geophys. Res. Lett. 39, L13202. doi: 10.1029/2012GL.

Pavlov, A.A., Glavin, D., Dworkin, J., McLain, H. \& Eigenbrode, J. (2016). Rapid degradation of the amino acids in Martian subsurface rocks and regolith due to exposure to cosmic rays, LPSC, \#2577.

Pinnick, V.T. et al. (2016). Mars Organic Molecule Analyzer (MOMA) mass spectrometer flight model integration and test, LPSC.

Poch, O., Kaci, S., Stalport, F., Szopa, C. \& Coll, P. (2014). Laboratory insights into the chemical and kinetic evolution of several organic molecules under simulated Mars surface UV radiation conditions. Icarus 242, 50-63.

Poch, O., Jaber, M., Stalport, F., Nowak, S., Georgelin, T., Lambert, J.-F., Szopa, C. \& Coll, P. (2015). Effect of nontronite smectite clay on the chemical evolution of several organic molecules under simulated Mars surface UV radiation conditions. Astrobiology 15(3), 221-237. doi: 10.1089/ast.2014.1230.

Quinn, R.C. \& Zent, A.P. (1999). Peroxide-modified titanium dioxide: a chemical analog of putative Martian soil oxidants. Orig. Life Evol. Biosph. 29, 59-72.

Ruff, S.W. \& Farmer, J. (2015). New observations reveal a former hot spring environment with high habitability and preservation potential in Gusev crater, Mars, LPSC, Abstr. \#1613.

Ruff, S.W. \& Farmer, J. (2016). Evidence for an alkali chloride hydrothermal system in the Columbia Hills, Mars, LPSC, 2827.

Siljeström, S. et al. (2014). Comparison of prototype and laboratory experiments on MOMA GCMS: results from the AMASE11 Campaign. Astrobiology 14(9), 780-797. doi: 10.1089/ast.2014.1197.

Smith, M.L., Claire, M.W., Catling, D.C. \& Zahnle, K.J. (2014). The formation of sulfate, nitrate and perchlorate salts in the Martian atmosphere. Icarus 231, 51-64. 
Soffen, G.A. \& Snyder, C.W. (1976). The first viking mission to mars. Science 193, 759-766. doi: 10.1126/science.193.4255.759.

Steele, A. et al. (2012). A reduced organic carbon component in Martian basalts. Science 337, 212-215. doi: 10.1126/science.1220715.

Steininger, H., Goesmann, F. \& Goetz, W. (2012). Influence of magnesium perchlorate on the pyrolysis of organic compounds in Mars analogue soils. Planet. Space Sci. 71, 9-17.

ten Kate, I.L. (2010). Organics on Mars? Astrobiology 10(6), 589-603. doi: 10.1089/ast.2010.0498.
Thompson, B.J. \& Schultz, P.H. (2007). The geology of the Viking Lander 2 site revisited. Icarus 191, 505-523.

Vaniman, D.T. et al. (2014). Mineralogy of a mudstone at Yellowknife Bay, Gale Crater, Mars. Science 343, 1243480-1. doi: 10.1126/science. 1243480.

Williams, R.M.E. et al. (2013). Martian fluvial conglomerates at gale crater. Science 340, 1068-1072. doi: 10.1126/science.1237317.

Yen, A.S., Kim, S.S., Hecht, M.H., Frant, M.S. \& Murray, B. (2000). Evidence that the reactivity of the Martian soil is due to superoxide ions. Science 289, 1909-1912. 